\title{
Estudo comparativo da eficácia do etanol e do ácido L-glutâmico na prevenção da calcificação das cúspides e parede aórtica porcina: estudo experimental em ratos
}

\author{
George Ronald SONCINI DA ROSA*, Francisco Diniz Affonso da COSTA* **, Lismari MESQUITA*, \\ Iseu de Santo Elias Affonso da COSTA*
}

RBCCV 44205-585

Soncini da Rosa GR, Costa FDA, Mesquita L, Costa ISEA - Estudo comparativo da eficácia do etanol e do ácido L-glutâmico na prevenção da calcificação das cúspides e parede aórtica porcina: estudo experimental em ratos. Rev Bras Cir Cardiovasc 2002; 17(2): 40-51.

RESUMO: Introdução: As cúspides porcinas tratadas com glutaraldeído (GDA) são um dos tecidos biológicos mais utilizados em biopróteses, porém a calcificação tardia pós-implante constitui a causa predominante de sua falência.

Objetivo: Analisar comparativamente dois métodos de prevenção da calcificação (etanol $80 \%$ e ácido L-glutâmico 0,8\%) em cúspide e parede aórtica porcina implantadas no subcutâneo em ratos, tendo como grupo controle as cúspides e os segmentos de parede aórtica fixadas em glutaraldeído (GDA), num período de 15, 30 e 60 dias após implante.

Material e Métodos: Foram utilizados 45 ratos jovens, distribuídos em 3 grupos contendo 15 animais cada, que por sua vez foram subdivididos em 3 subgrupos de 5 animais, nos quais foram implantados, em 2 bolsas no subcutâneo, uma cúspide e um segmento de parede aórtica em cada. Em cada grupo assim nominados: GDA (grupo controle), E80\% (grupo cujas estruturas foram pré-tratadas com etanol $80 \%$ ) e o AG 0,8\% (grupo cujas estruturas foram pré-tratadas com ácido L-glutâmico $0,8 \%$ ) foram realizadas a mensuração do cálcio e análise microscópica quanto à presença de calcificação (localização e intensidade da mesma) e de Infiltrado inflamatório (localização e tipo), no período de 15, 30 e 60 dias após implante.

Resultados: Na mensuração do cálcio na cúspide aórtica encontrou-se no grupo E80\% 15 dias $(1,30 \pm 0,21 \mathrm{mg}$ cálcio/mg tecido), E80\% 30 dias (1,05 $\pm 0,22 \mathrm{mg}$ cálcio/mg tecido) e E80\% 60 dias $(0,53 \pm 0,42 \mathrm{mg}$ cálcio/mg tecido); no grupo AG 0,8\% 15 dias $(12,17 \pm 0,66 \mathrm{mg}$ cálcio/mg

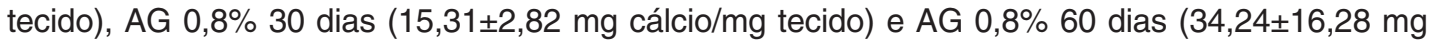
cálcio/mg tecido) com o grupo controle GDA 15 dias (12,44 $\pm 2,26 \mathrm{mg}$ cálcio/mg tecido), GDA 30

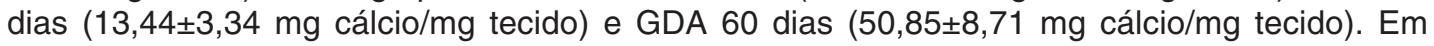
relação à mensuração do cálcio na parede aórtica, encontrou-se no grupo de E80\% 15 dias (4,62 $\pm 0,68 \mathrm{mg}$ cálcio/ $\mathrm{mg}$ tecido), E80\% 30 dias $(9,47 \pm 2,59 \mathrm{mg}$ cálcio/mg tecido) e E80\% 60 dias $(23,56 \pm 7,75 \mathrm{mg}$ cálcio/mg tecido) no grupo de AG 0,8\% 15 dias $(4,31 \pm 0,85 \mathrm{mg}$ cálcio/mg

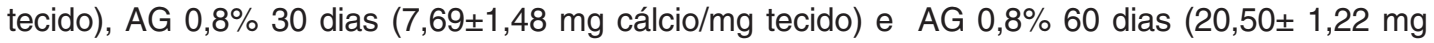
cálcio/mg tecido) com o grupo controle GDA 15 dias (7,34 $\pm 1,32 \mathrm{mg}$ cálcio/mg tecido), GDA 30 dias $(9,28 \pm 0,76 \mathrm{mg}$ cálcio/mg tecido) e GDA 60 dias (27,60 $1,08 \mathrm{mg}$ cálcio/mg tecido). $\mathrm{Na}$ avaliação microscópica da cúspide aórtica houve uma progressiva calcificação naquelas subme-

Trabalho realizado no Departamento de Cirurgia Experimental da Disciplina de Técnica Operatória da Pontifícia Universidade Católica do Paraná (PUC-PR). Curitiba, PR, Brasil.

Recebido para publicação em fevereiro de 2002.

* Da Santa Casa de Misericórdia de Curitiba.

** Departamento de Cirurgia Experimental da Disciplina de Técnica Operatória da Pontifícia Universidade Católica do Paraná.

Endereço para correspondência: George R. Soncini da Rosa. Av. Silva Jardim, 2939. Curitiba, PR, Brasil. CEP: 80240-020 Tel.: (41) 262.9053, cel (41)9979.2789, Fax (41) 262-0714. e-mail: soncini@bsi.com.br 
Soncini da Rosa GR, Costa FDA, Mesquita L, Costa ISEA - Estudo comparativo da eficácia do etanol e do ácido L-glutâmico na prevenção da calcificação das cúspides e parede aórtica porcina: estudo experimental em ratos. Rev Bras Cir Cardiovasc 2002; 17(2): 40-51.

tidas à fixação com GDA. Este processo foi parcialmente encontrado com o AG 0,8\% e totalmente ausente com o E80\%. Quanto à avaliação referente aos segmentos da parede aórtica, também evidenciou-se progressiva calcificação, não sendo inibida pelos tratamentos com AG $0,8 \%$ e E80\%.

Conclusões: $O$ pré-tratamento com etanol a $80 \%$ inibiu a calcificação nas cúspides aórticas porcinas, entretanto, não teve a mesma eficácia na parede aórtica. Contudo, o ácido L-glutâmico a 0,8\% demonstrou minimizar a calcificação na parede aórtica. Estudos devem ser feitos para evidenciar se a ação anticalcificante do etanol a $80 \%$ mantém-se nas biopróteses aórticas porcinas se estas forem implantadas no sistema circulatório.

DESCRITORES: Bioprótese, conservação. Etanol, farmacologia. Ácido glutâmico, farmacologia. Calcificação fisiológica.

\section{INTRODUÇÃO}

Cirurgiões vêm investigando e tentando desenvolver um substituto valvar cardíaco ideal há muitos anos. De modo geral, os substitutos valvares cardíacos são divididos em dois tipos: as próteses mecânicas e as biológicas. Estas, por sua vez, podem ser fabricadas com tecido humano ou animal. As próteses de tecidos animal são manufaturadas com pericárdio bovino ou com cúspides porcinas, podendo, ou não, incluir segmento de parede aórtica ${ }^{(1)}$.

Não obstante aos avanços das técnicas de reconstrução, muitos dos pacientes submetidos a procedimentos conservadores recebem substitutos valvares. A vantagem da maior durabilidade das válvulas mecânicas é contrabalançada pela necessidade do uso de anticoagulantes para evitar a ocorrência de tromboembolismo. Ao contrário, os portadores de próteses biológicas dispensam anticoagulação indefinida, mas estas são propensas à calcificação e degeneração, sendo necessárias reoperações para substituí-las ${ }^{(2,3)}$.

Tecidos biológicos têm sido usados como substituto valvar desde 1962, quando uma valva aórtica humana fresca foi transplantada (4). Posteriormente, foram introduzidas próteses manufaturadas com pericárdio bovino ${ }^{(5,6)}$, e dura-máter humana ${ }^{(7)}$. O uso do glutaraldeído para a fixação de próteses porcinas foi recebido como um considerável progresso nos processos de conservação dos tecidos biológicos ${ }^{(8)}$. Além da redução da antigenicidade do tecido heterólogo, a fixação obtida pela ligação covalente foi considerada como vantajosa ${ }^{(8)}$. Nos anos seguintes, a fixação pelo glutaraldeído foi amplamente empregada na manufatura de próteses porcinas e de pericárdio bovino ${ }^{(9,10)}$.

Hoje os tecidos valvares são utilizados em aproximadamente $40 \%$ na substituição valvar em todo mundo, porém com diferenças entre os países desenvolvidos e os subdesenvolvidos, onde por sua vez utilizase mais tecido biológico ${ }^{(1,4,11,12)}$.

A incidência de falência valvar em 10 anos é ao redor de 10 a $20 \%$ em pacientes adultos e 40 a $50 \%$ em 4 anos em crianças ${ }^{(13)}$.
O estresse mecânico e o depósito lipídico nas células dos folhetos aórticos porcinos decorrentes da fixação com GDA têm sido indicados como os principais fatores que influenciam a calcificação (14-17).

A suposição de que a calcificação possa estar relacionada ao uso do glutaraldeído despertou interesse no estudo de modificações no processo, como a adição de substâncias inibidoras da mineralização ou mesmo sua substituição por outros agentes fixadores.

Dentre os tratamentos investigados estão o emprego do etanol e do ácido L- glutâmico (AG), que se mostraram eficazes quando utilizados como anticalcificantes para o pericárdio bovino. $O$ etanol apresentou efeito anticalcificante no pericárdio bovino de implantes subcutâneos em ratos e de próteses mitrais em ovelhas ${ }^{(18-20)}$.

Vários estudos têm demonstrado a eficácia do etanol como inibidor da calcificação de biopróteses porcinas, sendo seu principal efeito a extração lipídica $(1,18,20,21)$.

O ácido L-glutâmico, utilizado para tratamento do pericárdio bovino, juntamente com o glutaraldeído, evidenciou diminuir sua toxicidade e melhorar a conservação das células endoteliais, tendo como resultado menor índice de calcificação (22-25).

Tendo em vista a necessidade de um tratamento anticalcificante eficaz, tanto para as cúspides quanto para a parede aórtica porcina, está sendo proposto um estudo comparativo entre o etanol e o ácido Lglutâmico na prevenção da calcificação nesta estruturas, com implante subcutâneo em ratos jovens, com a perspectiva de minimizar a calcificação e aumentar a durabilidade das biopróteses em pacientes jovens e crianças.

O objetivo deste trabalho será analisar comparativamente dois métodos de prevenção da calcificação (etanol $80 \%$ e ácido L-glutâmico 0,8\%) em cúspide e parede aórtica porcina implantadas no subcutâneo em ratos, tendo como grupo controle as cúspides e os segmentos de parede aórtica fixadas em glutaraldeído (GDA), num período de 15, 30 e 60 dias após implante. 
Soncini da Rosa GR, Costa FDA, Mesquita L, Costa ISEA - Estudo comparativo da eficácia do etanol e do ácido L-glutâmico na prevenção da calcificação das cúspides e parede aórtica porcina: estudo experimental em ratos. Rev Bras Cir Cardiovasc 2002; 17(2): 40-51.

\section{MATERIAL E MÉTODOS}

Este trabalho foi realizado no Laboratório de Cirurgia Experimental da Disciplina de Técnica Operatória da Pontifícia Universidade Católica do Paraná (PUCPR), no Laboratório da Cardioprótese Ltda. e Laboratório de Patologia da Santa Casa de Misericórdia de Curitiba.

Foi adotada a Nômina Anatômica Veterinária (1983). Respeitaram-se os princípios éticos de experimentação animal, conforme preconizado pelo Colégio Brasileiro de Experimentação Animal.

\section{Modelo Experimental}

Foram utilizados 45 ratos machos (Rattus norvegicus), clinicamente sadios da linhagem Wistar, com o peso entre 84 a $109 \mathrm{~g}$, proveniente do Biotério da Pontifícia Universidade Católica do Paraná. Os animais foram divididos em 3 grupos de 15. Cada grupo foi subdividido em 3 lotes de 5 animais, estudados depois de 15, 30 e 60 dias de observação.

- Grupo GDA ( $n=15)$ - (grupo controle) Cúspides e paredes aórticas porcinas conservadas em glutaraldeído implantadas em lojas subcutâneas na região dorsal de ratos.

- Grupo E $80 \%(n=15)$ - Cúspides e paredes aórticas porcinas pré-tratadas com glutaraldeído e após tratamento e conservação em solução de etanol a $80 \%$ implantadas em lojas subcutâneas na região dorsal de ratos.

- Grupo AG ( $n=15)$ - Cúspides e paredes aórticas porcinas pré-tratadas com glutaraldeído e após tratamento e conservação em solução de ácido L-glutâmico a 0,8\% implantadas nas lojas subcutâneas na região dorsal de ratos.

Os ratos foram mantidos no Biotério da PUC-PR, onde receberam ração balanceada para espécie (Nuvitab CR1â) durante todo o período de crescimento.

No momento do implante, foram submetidos a tricotomia da região dorsal e antissepsia com álcool iodado. Para a feitura das lojas subcutâneas, os animais foram anestesiados com éter sulfúrico durante todo procedimento.

\section{Anestesia}

O animal foi colocado em decúbito ventral na mesa operatória. A anestesia induzida via inalatória com éter sulfúrico e mantida durante todo o procedimento. Após o implante da cúspide e parede aórtica nas lojas na região dorsal, os animais foram colocados em gaiolas apropriadas, com cinco ratos cada.

\section{Obtenção das Cúspides e Paredes de Aorta Porcina}

As cúspides e paredes aórticas foram obtidas no Laboratório de Valvas Cardíacas (Cardiopróteseâ), onde foram preparadas conforme solicitação do pesquisador.

\section{Procedimento Químico}

Todas as cúspides aórticas foram obtidas de valvas aórticas de corações porcinos, obtendo-se então as 3 cúspides de cada valva. Após esta separação, foram também recortados segmentos da parede de aorta com tamanhos de $1 \mathrm{~cm} \times 1 \mathrm{~cm}$ e preparados com a mesma metodologia utilizada para as cúspides.

As 45 cúspides e os segmentos de paredes aórticas foram fixados em solução de glutaraldeído 0,6\% (UrcacidÒ) com 50mmol/L HEPES (Solução Tampão), pH 7.4, durante 24 horas em recipientes apropriados. Após 24 horas foram deixados em solução de glutaraldeído 0,2\% (GDA 0,2\%) (Urcacid Ò) (GDA 0,2\%) com solução HEPES durante 7 dias, para completar a fixação.

Após os 7 dias, a solução de GDA $0,2 \%$ foi trocada e as estruturas permaneceram por mais 24 horas em solução.

Depois de 24 horas, todas as cúspides e os segmentos de parede de aorta foram lavados 5 vezes com solução de soro fisiológico à temperatura ambiente.

Até esse momento todas as cúspides e os segmentos da parede de aorta foram fixados de maneira idêntica.

Terminada esta preparação básica, 15 cúspides e 15 segmentos de parede aórtica foram lavados 3 vezes em solução de soro fisiológico e colocados durante 24 horas em solução aquosa de ácido Lglutâmico a 0,8\%, pH 3.5 (Gibco BRL Ò). Depois desse período, foram lavados 5 vezes com solução de soro fisiológico e armazenados nesta última solução.

Quinze cúspides e os segmentos de parede de aorta foram lavados em soro fisiológico 3 vezes e colocados durante 24 horas sob agitação constante, em solução de etanol $80 \%$ (LabsynthÒ) com tampão HEPES à temperatura de $25^{\circ} \mathrm{C}$. Finalizado esse período, ambos foram lavados 5 vezes cada em soro fisiológico e armazenados nesta última solução. 


\begin{tabular}{|c|c|c|}
\hline \multicolumn{3}{|c|}{ GDA $0,6 \% \rightarrow 24$ horas } \\
\hline \multicolumn{3}{|c|}{$\downarrow$} \\
\hline \multicolumn{3}{|c|}{ GDA $0,2 \% \rightarrow 7$ dias } \\
\hline \multicolumn{3}{|c|}{$\downarrow$} \\
\hline \multicolumn{3}{|c|}{ GDA $0,2 \% \rightarrow 24$ horas } \\
\hline$\downarrow$ & $\downarrow$ & $\downarrow$ \\
\hline AC. L. Glutâmico 0,8\% & GDA $0,2 \%$ & Etanol $80 \%$ \\
\hline 24 horas & 24 horas & 24 horas \\
\hline$\downarrow$ & $\downarrow$ & $\downarrow$ \\
\hline Lavadas & Lavadas & Lavadas \\
\hline$\downarrow$ & $\downarrow$ & $\downarrow$ \\
\hline Implantadas & Implantadas & Implantadas \\
\hline
\end{tabular}

As 15 cúspides e paredes de aorta restantes foram mantidas em glutaraldeído e lavadas antes do implante, utilizadas como grupo controle.

\section{Técnica Operatória}

Os ratos foram tricotomizados na região dorsal, posicionados na mesa cirúrgica em decúbito ventral. A antissepsia da região operatória foi feita com uma solução de tintura de polivinilpirrolidona (PovidineÒ).

Foram realizadas incisões de aproximadamente 2 $\mathrm{cm}$ na região dorsal e confeccionadas duas lojas subcutâneas para o implante da cúspide e parede de aorta.

Para a sutura da incisão, foi utilizado fio de mononylon 3-0 monofilamentar (MononylonÒ, Ethicon).

\section{Observação Pós-Operatória}

Após o ato operatório, os ratos foram marcados com canetas especiais para identificação e colocados em gaiolas apropriadas. Em cada gaiola ficaram cinco ratos.

Os ratos foram mantidos com alimentação e cuidados usuais do biotério, observados e submetidos ao sacrifício em 15, 30 e 60 dias.

O sacrifício dos ratos foi feito por intoxicação anestésica com éter sulfúrico em recipiente fechado.

Quando da retirada das peças, foi realizada incisão longitudinal na região dorsal e removidas as peças, para análise microscópica e mensuração do cálcio por espectrofotometria de absorção atômica com atomização em chama.

\section{Análise Morfológica}

\section{Análise Microscópica}

As peças cirúrgicas, tanto os segmentos de aorta quanto as cúspides, foram fixadas em solução de formalina a $10 \%$ e encaminhadas para análise microscópica.

Os exames histológicos foram realizados por um mesmo observador, sem conhecimento do grupo ao qual pertencia o espécime.

A preparação do material histológico seguiu os métodos de histotécnica adotados pelo Laboratório de Patologia da Santa Casa de Curitiba. Após fixação em solução de formalina tamponada a 10\%, o material da amostra foi desidratado pelo álcool etílico, em concentrações progressivas de $70 \%$ a $100 \%$, diafanizado por impregnação com xilol e imerso em parafina a $60 \%$, para constituição dos blocos.

Realizaram-se cortes de 2 a $4 \mathrm{~mm}$ de espessura, corados com hematoxilina-eosina (H\&E) e von Kossa (método específico para visualização de calcificação). Utilizou-se microscópio tetraocular (American Optical) para a análise.

Para a análise dos achados histopatológicos, adotou-se a seguinte classificação:

I Cúspide Aórtica
I- Calcificação:
1-Localização
| 1a - focal
| 1b - multifocal
I 1c - difusa
I 1d - ausente.
2 - Intensidade
I 2 a- discreta
I 2 b - moderada
I 2 c - acentuada

II - Infiltrado inflamatório:

1 - Localização

II $1 \mathrm{a}-$ focal

II $1 b$ - difuso

II $1 \mathrm{c}-$ ausente

2 - Tipo

II $2 \mathrm{a}$ - agudo

II $2 \mathrm{~b}$ - crônico discreto

II 2c - granulomatoso moderado

- Parede de Aorta

Para a parede de aorta foi utilizado o mesmo protocolo histológico da cúspide aórtica, com as mencionadas subdivisões.

Mensuração do Cálcio

As amostras de cúspide aórtica e parede de aorta 
Soncini da Rosa GR, Costa FDA, Mesquita L, Costa ISEA - Estudo comparativo da eficácia do etanol e do ácido L-glutâmico na prevenção da calcificação das cúspides e parede aórtica porcina: estudo experimental em ratos. Rev Bras Cir Cardiovasc 2002; 17(2): 40-51.

foram submetidas à solubilização com ácido clorídrico e enviadas ao Laboratório do Instituto de Tecnologia para o Desenvolvimento (LactecÒ), da Universidade Federal do Paraná, onde a determinação quantitativa do cálcio foi realizada por espectroscopia de absorção atômica, com espectrômetro Perkin Elmer, 4100.

A quantidade total de cálcio foi expressa em $\mathrm{mg}$ por amostra e extrapolada para $\mathrm{mg} / \mathrm{mg}$ de tecido seco pré-implante. Deste modo, foi possível estimar a quantidade de cálcio incorporado por miligrama de tecido seco implantado e não do tecido seco explantado, cujo peso reflete não só a quantidade de cálcio incorporada como também a infiltração das células do hospedeiro.

\section{Metodologia Estatística}

Recorreu-se à análise descritiva dos dados pelas tabelas, quadros e gráficos. Foram utilizados a Análise de Variância (ANOVA) e os testes paramétrico "t de Student" e o não-paramétrico "Mann-Whitney", com auxílio do software "Primer of Biostatistics".

$O$ teste da ANOVA também foi utilizado para amostras relacionadas ("Repetead Measures ANOVA"), os demais para amostras independentes. O nível de significância mínimo adotado foi de 5\% $(0,05)$.

\section{RESULTADOS}

Não houve óbito durante o procedimento cirúrgico ou no período pós-operatório.

\section{Análise Microscópica}

\section{Calcificação}

Cúspide Aórtica

Conforme observa-se nas Tabelas 1 e 2, houve calcificação progressiva das cúspides valvares submetidas ao tratamento com GDA (Figuras 1 e 2). Esse processo foi parcialmente encontrado com o ácido Lglutâmico (Figura 3) e totalmente ausente com 0 etanol (Figuras 4, 5 e 6).

E em relação à intensidade, também foi constatada ausência de calcificação.

Parede de Aorta

Os segmentos de parede aórtica também demonstraram calcificação progressiva, não sendo inibidos pelos tratamentos com ácido L-glutâmico e etanol (Figuras 7, 8 e 9).

Em relação à intensidade da calcificação, verificou-se que tanto os segmentos submetidos à conservação com etanol $80 \%$ quanto os submetidos ao GDA apresentaram intensidade moderada aos 15 e 30 dias. Aos 60 dias ambos apresentaram intensidade moderada (20\%) ou acentuada ( $80 \%)$.
TABELA 1. CALCIFICAÇÃO QUANTO À LOCALIZAÇÃO, SEGUNDO OS MÉTODOS DE CONSERVACCÃO E OS TEMPOS DE OBSERVAÇÂO CÚSPIDE AÓRTICA

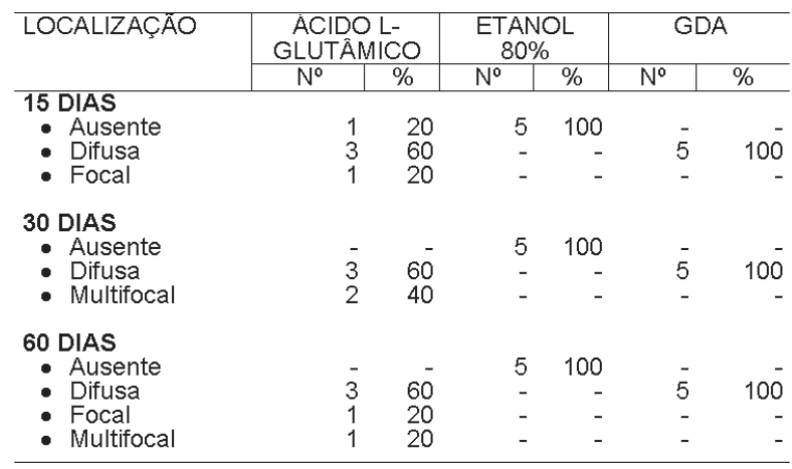

TABELA 2. CALCIFICAÇÃO QUANTO À INTENSIDADE, SEGUNDO OS MÉTODOS DE CONSERVAÇÃO E OS TEMPOS DE OBSERVAÇÃ̃O CÚSPIDE AÓRTICA

\begin{tabular}{|c|c|c|c|c|c|c|}
\hline \multirow[t]{2}{*}{ INTENSIDADE } & \multicolumn{2}{|c|}{$\begin{array}{c}\text { ACIDO L- } \\
\text { GLUTÂMICO }\end{array}$} & \multicolumn{2}{|c|}{$\begin{array}{c}\text { ETANOL } \\
80 \%\end{array}$} & \multicolumn{2}{|c|}{ GDA } \\
\hline & $N^{0}$ & $\%$ & $\mathrm{~N}^{0}$ & $\%$ & $\mathrm{~N}^{\circ}$ & $\%$ \\
\hline \multicolumn{7}{|l|}{15 DIAS } \\
\hline - Ausente & 1 & 20 & 5 & 100 & & - \\
\hline - Discreta & 1 & 20 & - & - & & - \\
\hline - Moderada & 3 & 60 & - & - & & 100 \\
\hline $\begin{array}{l}\text { - Acentuada } \\
30 \text { DIAS }\end{array}$ & 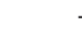 & - & - & - & & - \\
\hline - Ausente & - & - & 5 & 100 & & - \\
\hline - Moderada & 3 & 60 & - & - & & - \\
\hline - Acentuada & 2 & 40 & - & - & & 100 \\
\hline \multicolumn{7}{|l|}{60 DIAS } \\
\hline - Ausente & . & - & 5 & 100 & & - \\
\hline - Moderada & 1 & 20 & - & - & & - \\
\hline - Acentuada & 4 & 80 & - & - & & 100 \\
\hline
\end{tabular}

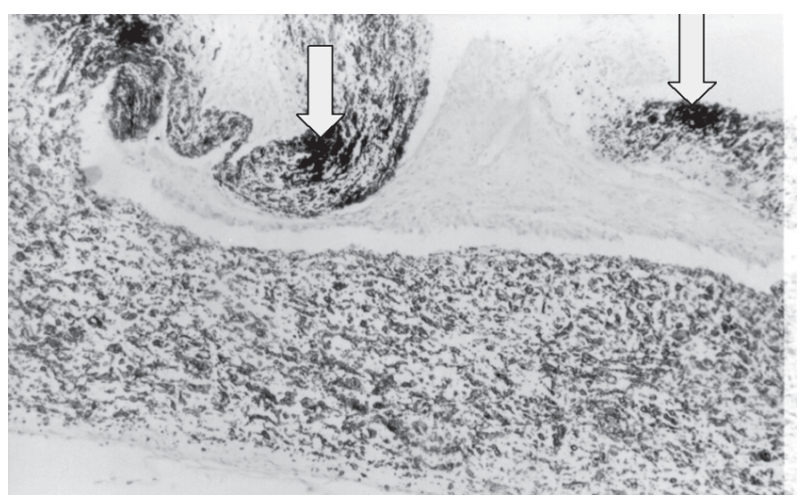

Fig. 1 - Fotomicrografia mostrando corte transversal da cúspide aórtica tratada com glutaraldeído, com sinais de importante calcificação após 15 dias de implante. GDA subgrupo 15 dias (von Kossa 100x). 
Soncini da Rosa GR, Costa FDA, Mesquita L, Costa ISEA - Estudo comparativo da eficácia do etanol e do ácido L-glutâmico na prevenção da calcificação das cúspides e parede aórtica porcina: estudo experimental em ratos. Rev Bras Cir Cardiovasc 2002; 17(2): 40-51.

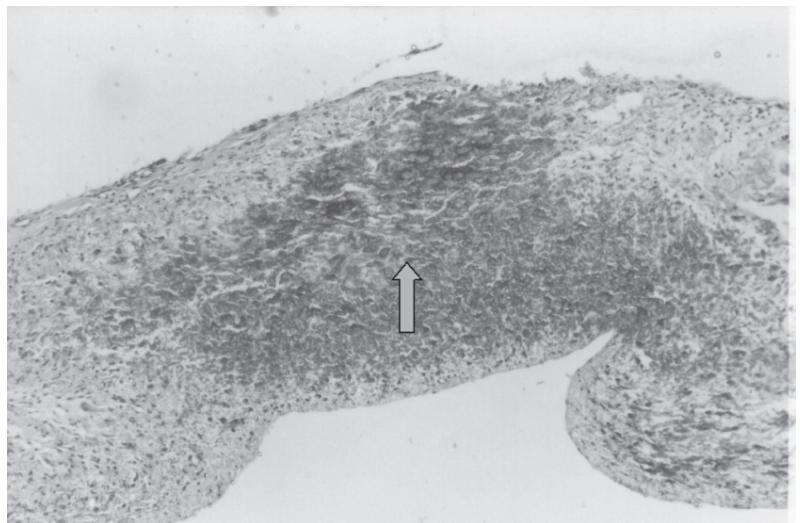

Fig. 2 - Fotomicrografia mostrando corte transversal da cúspide aórtica tratada com glutaraldeído, com sinais de importante calcificação após 30 dias de implante. GDA subgrupo 30 dias (H\&E 100x).

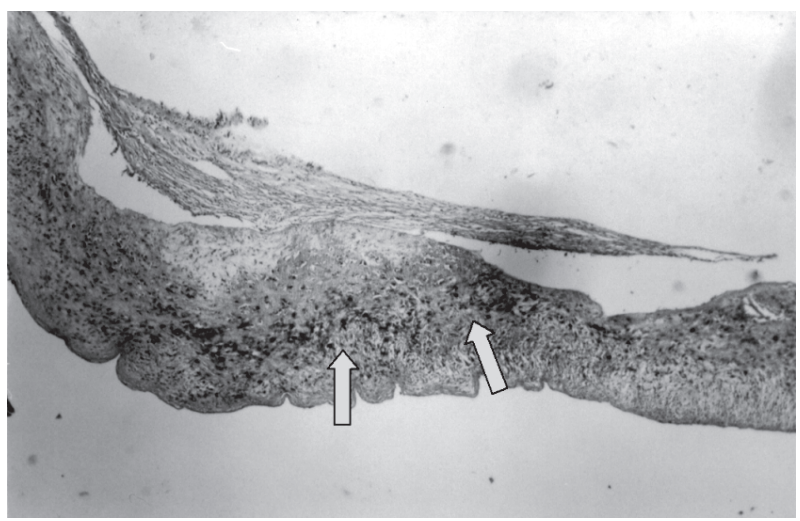

Fig. 3 - Fotomicrografia mostrando corte transversal da cúspide aórtica tratada com ácido L-glutâmico, com sinais de importante calcificação após 15 dias de implante. AG subgrupo 15 dias (H\&E 40x).

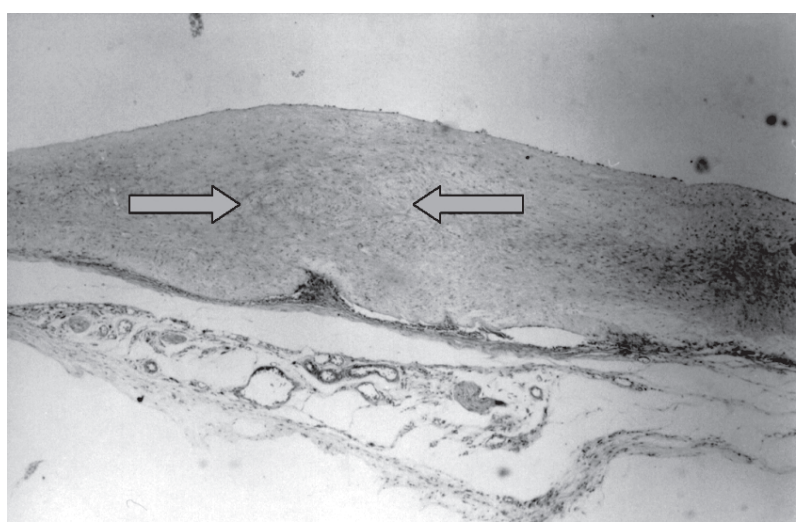

Fig. 4 - Fotomicrografia mostrando corte transversal da cúspide aórtica tratada com etanol $80 \%$, sem sinais de calcificação após 15 dias de implante. E80\% subgrupo 15 dias (von Kossa 40x).

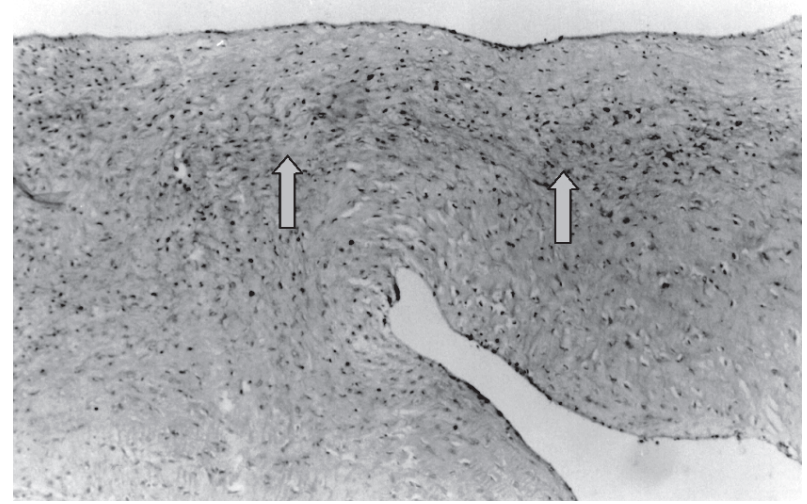

Fig. 5 - Fotomicrografia mostrando corte transversal da cúspide aórtica tratada com etanol $80 \%$, sem sinais de calcificação após 30 dias de implante. E $80 \%$ subgrupo 30 dias (von Kossa 100x).

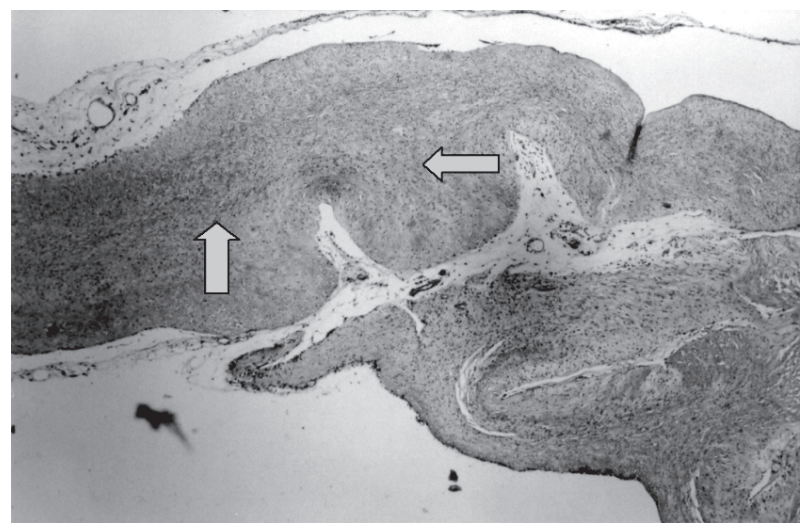

Fig. 6 - Fotomicrografia mostrando corte transversal da cúspide aórtica tratada com etanol $80 \%$, sem sinais de calcificação após 60 dias de implante. E $80 \%$ subgrupo 60 dias (H\&E 40x).

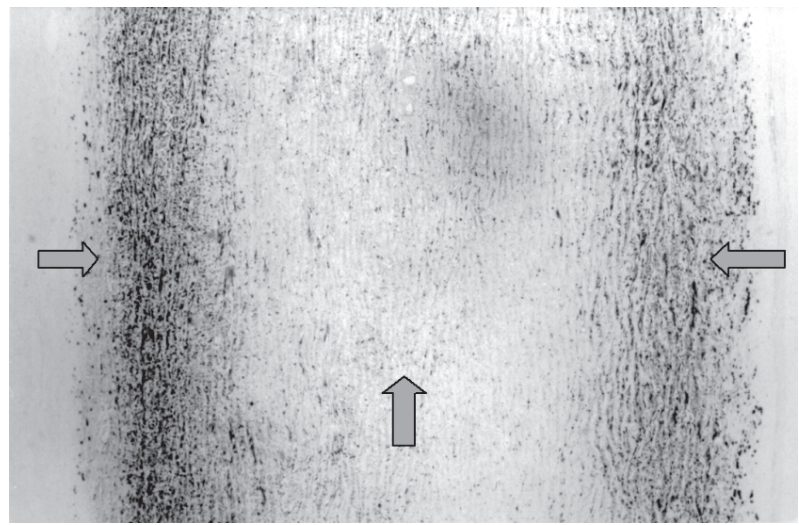

Fig. 7 - Fotomicrografia mostrando corte longitudinal da parede aórtica tratada com etanol $80 \%$, apresentando calcificação difusa e moderada após 15 dias do implante. E $80 \%$ subgrupo 15 dias (von Kossa 100x). 


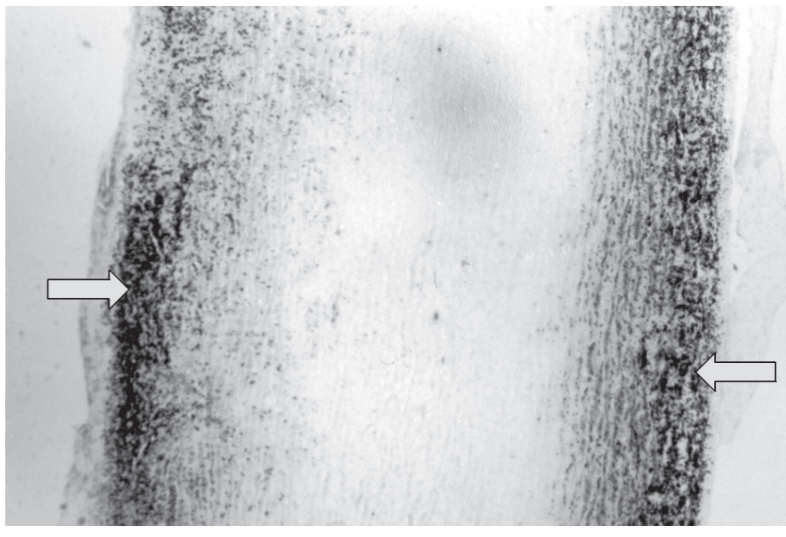

Fig. 8 - Fotomicrografia mostrando corte longitudinal de parede aórtica tratada com glutaraldeído, apresentando calcificação difusa e acentuada após 30 dias do implante. GDA subgrupo 30 dias (von Kossa 100x).

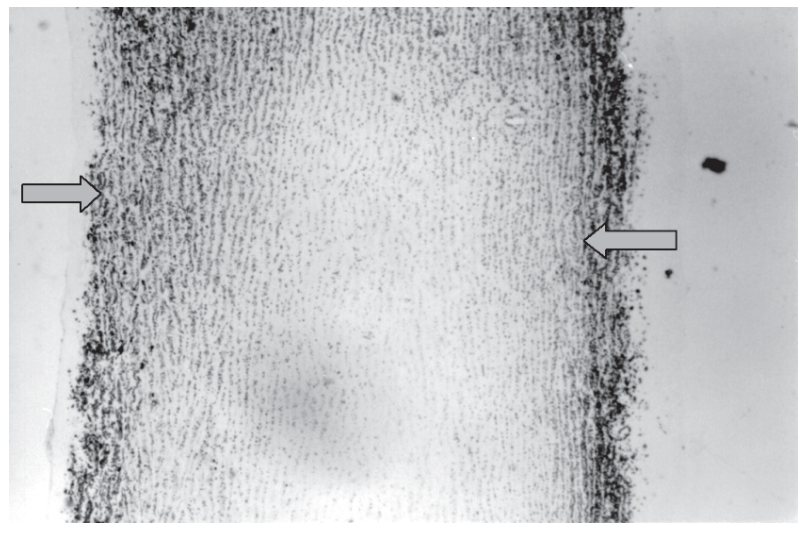

Fig. 9 - Fotomicrografia mostrando corte longitudinal da parede aórtica tratada com ácido L-glutâmico, apresentando calcificação difusa e acentuada, após 60 dias do implante. AG subgrupo 60 dias (von Kossa 100x).

Infiltrado Inflamatório

Cúspide Aórtica

Em relação ao infiltrado inflamatório na cúspide aórtica, observa-se que o método de conservação no qual utilizouse o ácido L-glutâmico apresentou localização focal, em todos os casos do período de 60 dias.

Em relação à intensidade, observa-se que o método de conservação do ácido L-glutâmico permaneceu inalterado em todos os tempos de observação.

\section{Parede de Aorta}

Em relação ao infiltrado inflamatório na parede de aorta, observa-se que todos os métodos de conservação apresentaram localização focal, em todos os tempos de observação.

Em relação à intensidade, verifica-se que o método de conservação do ácido L-glutâmico apresentou em todos os casos, intensidade crônico discreto para o período de 60 dias.

\section{Mensuração do Cálcio}

Na comparação da mensuração do cálcio, da cúspide aórtica, entre os métodos de consenvação (grupo de estudo), em cada tempo de observação, separadamente, foi constatada significância estatística, em todos os tempos de observação:

- O método de conservação etanol $80 \%$ apresentou menor mensuração do cálcio, em 15 dias $(\mathrm{p}<0,0001)$ (Gráfico 1); 30 ( $p<0,0001)$ (Gráfico 2) e 60 ( $p<0,0001)$ (Gráfico 3) No Gráfico 4 observa-se a análise conjunta nos tempos de 15, 30 e 60 dias;

Na comparação da mensuração do cálcio, da parede de aorta, entre os métodos de preparação (grupo de estudo), em cada tempo de observação, separadamente, foi constatada significância estatística apenas para o período de 15 dias:

- GDA apresentou maior quantidade do cálcio, de modo geral ( $p<0,0001)$, e quando comparado ao ácido Lglutâmico $(p=0,003)$ e ao etanol 80\% ( $p=0,003)$ (Gráfico 5);

\section{GRÁFICO1 \\ MENSURAÇÃO DO CÁLCIO NA CÚSPIDE AÓRTICA, NOS MÉTODOS \\ DE CONSERVAÇÃO - 15 DIAS}
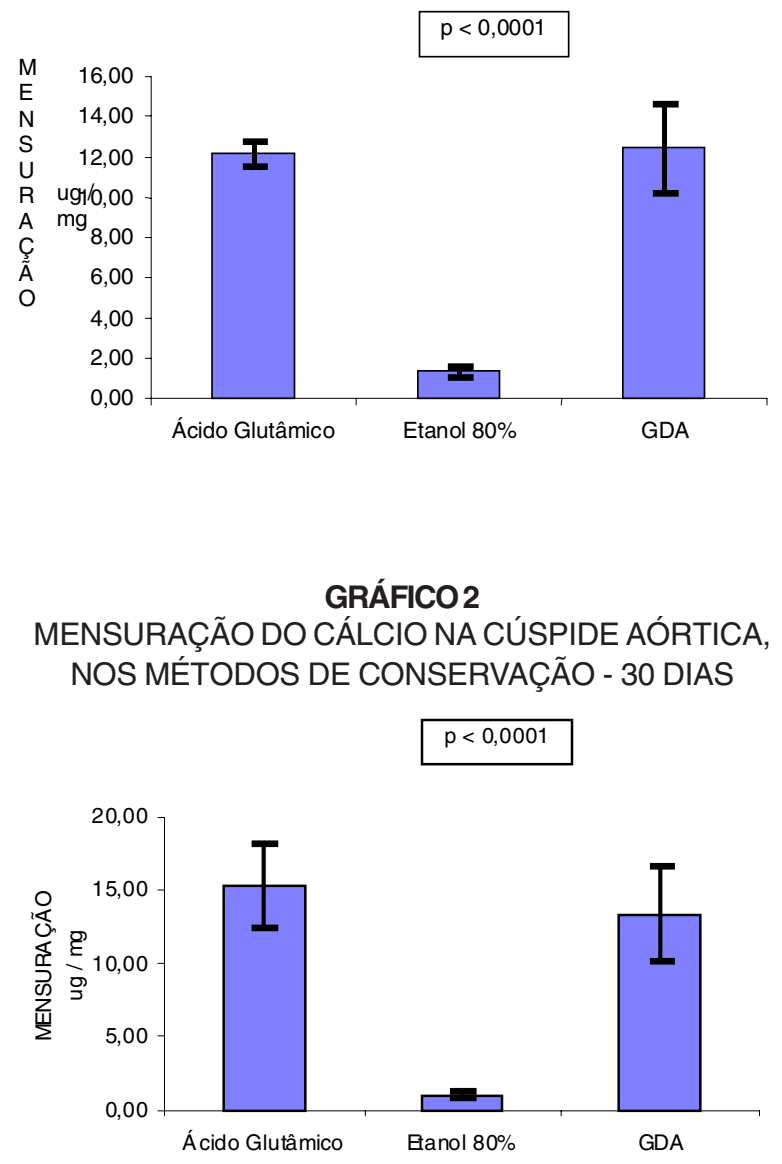


\section{GRÁFICO3 \\ MENSURAÇÃO DO CÁLCIO NA CÚSPIDE AÓRTICA, NOS MÉTODOS DE CONSERVAÇÃO - 60 DIAS}

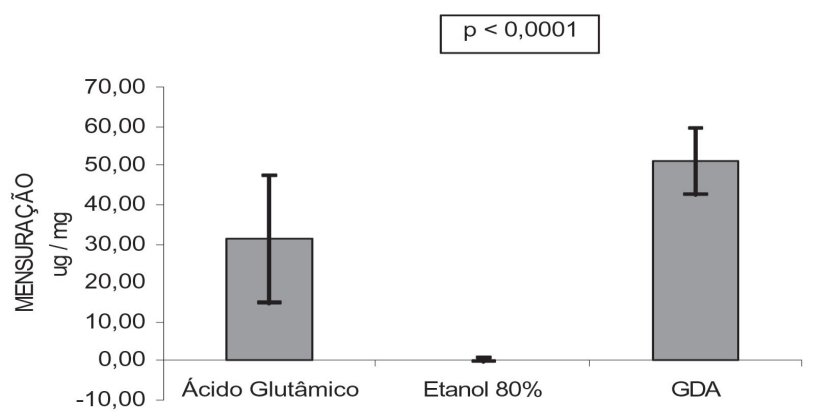

GRÁFICO 4

MENSURAÇÃO DO CÁLCIO NA CÚSPIDE AÓRTICA, NOS MÉTODSOS DE CONSERVAÇÃO E NOS TEMPOS DE OBSERVAÇÃO

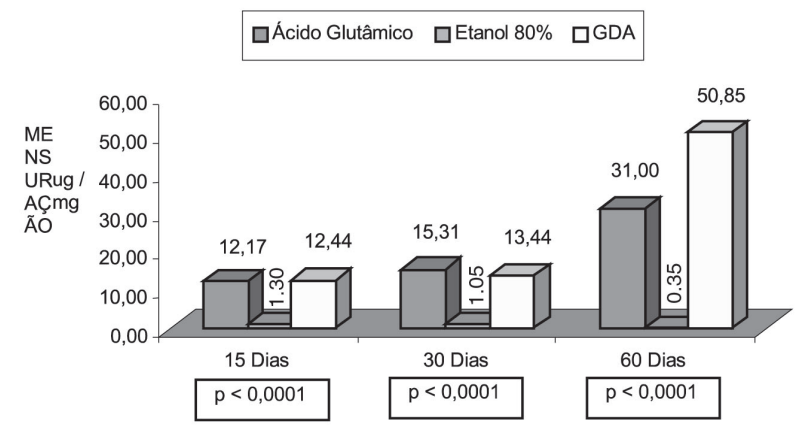

GRÁFICO 5

MENSURAÇÃO DO CÁLCIO NA PAREDE DE AORTA, NOS MÉTODOS DE CONSERVAÇÃO - 15 DIAS

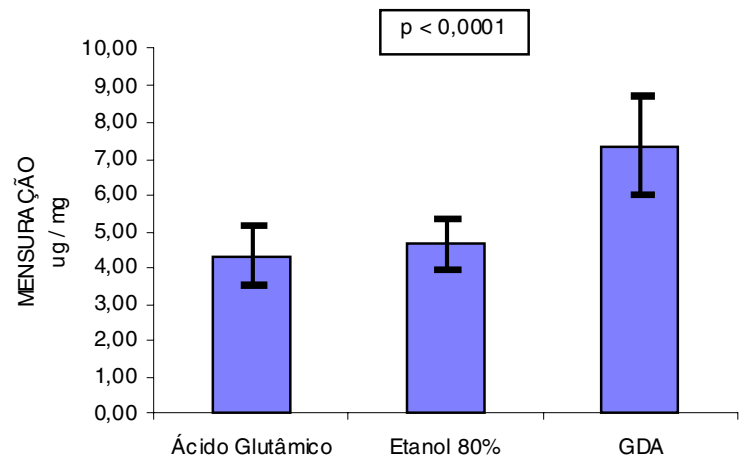

\section{GRÁFICO 6 \\ MENSURAÇÃO DO CÁLCIO NA PAREDE DE AORTA, NOS MÉTODOS DE CONSERVAÇÃO - 60 DIAS}

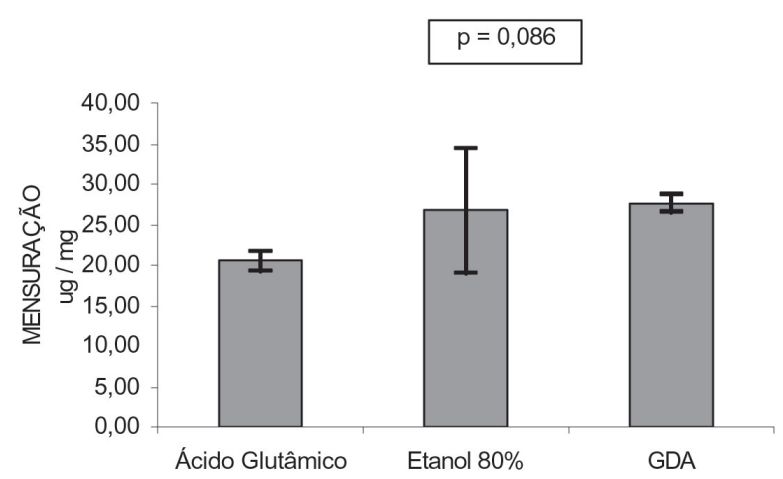

GRÁFICO7

MENSURAÇÃO DO CÁLCIO NA PAREDE DE AORTA, NOS MÉTODOS DE CONSERVAÇÃO E NOS TEMPOS DE OBSERVAÇÃO

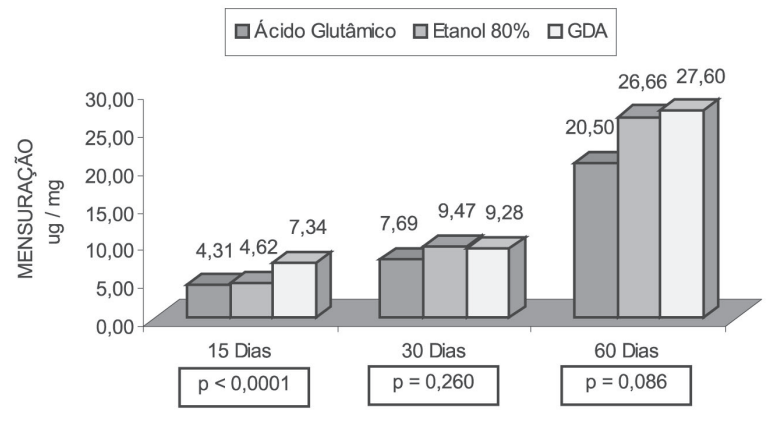

Ressalta-se que aos 60 dias foi constatada diferença significativa apenas na comparação do ácido Lglutâmico com o GDA, ou seja, também maior mensuração de cálcio no GDA $(p<0,0001)$.

Também foram correlacionados os valores do etanol $80 \%$, nos diferentes tempos de observação, sendo constatada maior mensuração do cálcio em 60 dias $(p<0,0001)$ (Gráficos 6 e 7). O ácido Lglutâmico e o GDA não foram analisados.

\section{COMENTÁRIOS}

Desde os primeiros implantes de valvas porcinas tratadas por glutaraldeído, várias técnicas têm sido usadas para minimizar a calcificação ${ }^{(21,26)}$. 
Soncini da Rosa GR, Costa F D A, Mesquita L, Costa I S E A - Estudo comparativo da eficácia do etanol e do ácido L-glutâmico na prevenção da calcificação das cúspides e parede aórtica porcina: estudo experimental em ratos. Rev Bras Cir Cardiovasc 2002; 17(2): 40-51.

O risco de falência estrutural das biopróteses porcinas é fortemente dependente da idade do receptor. Em pacientes com idade inferior a 35 anos, há falência quase uniforme cinco anos após implantação. Já em pacientes acima de 65 anos, apenas cerca de $10 \%$ sofrem disfunção nos 10 anos seguintes ao implante $(15,27,28)$.

Com a intenção de tornar mínima a calcificação, SCHOEN et al. ${ }^{(22)}$ utilizaram cátions mono, di, ou trivalentes durante a fixação em glutaraldeído, mas suas ações não se mostraram satisfatórias. Hidroxi e amino-difosfonatos e cátions metálicos foram também testados, mas os altos teores necessários interferiram no crescimento ósseo ${ }^{(21,22)}$.

O pré-tratamento com detergente (SDS Tween 80 ) pode inibir a calcificação pela remoção dos fosfolipídeos do substrato. Entretanto, os detergentes afetam a superfície da membrana e as fibras colágenas, resultando, por vezes, em marcada diminuição da durabilidade das biopróteses ${ }^{(18,29,30)}$.

Recentemente, o ácido amino oléico usado como detergente demonstra prevenir a calcificação das biopróteses porcinas ${ }^{(31-33)}$. Os resultados mostraram que o ácido amino oléico reduz significativamente a calcificação dos folhetos das biopróteses implantadas na posição aórtica em ovelhas. Entretanto, os resultados quanto à estabilidade em vivo e a possibilidade de degradação do ácido amino oléico remanescente no tecido necessitam ser resolvidos ${ }^{(18,31)}$.

Outra alternativa estudada são bisfosfonatos, que agem bloqueando o crescimento dos cristais de hidroxiapatita no tecido bioprotético, cujo uso sistêmico mostra efeitos adversos no metabolismo do cálcio nos ossos que leva a seu enfraquecimento (34).

Demonstrou-se que, quando os bisfosfonatos são colocados junto a folhetos de valvas porcinas implantadas no subcutâneo de ratos, sua liberação lenta e local inibe a calcificação, sem efeitos adversos observados com o uso sistêmico ${ }^{(35)}$.

Os etanohidroxibisfosfonatos e $\circ \mathrm{FeCl}_{3}$ mostraram efeito sinérgico na inibição da calcificação de segmentos de parede aórtica de ratos implantados em animais da mesma espécie. Entretanto, o emprego de liberação sistêmica controlada destes mesmos agentes foi menos efetivo na prevenção do depósito de cálcio em próteses aórticas porcinas (36).

Outro agente anticalcificante, o aminopropilhidroxibisfosfonato, mostrou ser efetivo em folhetos aórticos porcinos implantados no subcutâneo de ratos. Porém, quando biopróteses porcinas foram estudadas no sistema circulatório, o efeito anticalcificante não foi demonstrado ${ }^{(37,38)}$.

O alumínio é associado à osteomalácia em pacientes mantidos em diálise renal. Por isso, realizaram-se estudos com sais metálicos contendo $\mathrm{Al}^{3+} \mathrm{e}$
$\mathrm{Fe}^{3+}$, visando prevenir a calcificação.

As cúspides aórticas porcinas foram incubadas nestes íons metálicos trivalentes, observando-se marcada ação anticalcificante em implantes, mesmo com baixas concentrações ${ }^{(39)}$. Estudos morfológicos com os tecidos das biopróteses pré-tratadas com alumínio e cloridrato de ferro revelaram que o $\mathrm{Al}^{3+} \mathrm{e}_{\mathrm{O} \mathrm{Fe}} \mathrm{Fe}^{3+}$ são os responsáveis pela desvitalização celular.

Mesmo havendo diferenças entre o perfil das lipoproteínas humanas e os dos ratos e ovelhas, demonstrando diversidade no metabolismo de cálcio destas espécies, nelas coexistem doenças valvares e cardiovasculares. Entretanto, os estudos de microscopia e patologia ultra-estrutural indicam que o material clínico e modelo animal são comparáveis $(33,40,41)$.

VYAVAHARE et al. ${ }^{(18)}$ estudaram os efeitos de várias concentrações do etanol e mostraram que a $80 \%$ ele inibe a calcificação de cúspides aórticas implantadas no subcutâneo de ratos ou no sistema circulatório de ovelhas, como substituto mitral. Acreditam que a extração do colesterol e fosfolipídeos seja o principal mecanismo de sua ação anticalcificante, embora haja outros fatores que podem influenciar a mineralização do tecido bioprotético.

No presente estudo visou-se identificar uma substância que seja anticalcificante eficaz, tanto para as cúspides quanto para a parede aórtica porcina. Com este fim, foram comparados os achados deste estudo com o etanol a $80 \%$ com obtidos com outras concentrações deste por VYAVAHARE et al. ${ }^{(18)} \mathrm{em}$ cúspides aórticas porcinas. Confrontaram-se, também, estes dados com os apresentados por GRIMM et al. (24), que obtiveram significativa ação anticalcificante com tratamento do pericárdio bovino com o ácido L-glutâmico a 0,8\%.

Os dados deste trabalho com a mensuração do teor de cálcio nas cúspides aórticas tratadas com etanol a $80 \%$ e implantadas no subcutâneo de ratos, nos intervalos de 15,30 e 60 dias após o implante, demonstraram significativa inibição da calcificação. Os valores encontrados aproximam-se dos referidos por VYAVAHARE et al. ${ }^{(18,20)}$. Já os segmentos de parede aórtica tratados pelo etanol a $80 \%$ não demonstraram eficácia de sua ação, quando comparados aos valores do teor de cálcio obtidos com o tratamento pelo glutaraldeído. O estudo histológico confirma este fato, o que vai ao encontro dos achados da literatura (18).

O ácido L-glutâmico a 0,8\% não foi capaz de inibir a calcificação das cúspides valvares porcinas, pois os valores da mensuração do teor de cálcio não diferiram dos encontrados no grupo controle.

Entretanto, os resultados observados com o segmentos de parede aórtica indicam melhor ação anticalcificante do ácido L-glutâmico a 0,8\%, compa- 
Soncini da Rosa GR, Costa F D A, Mesquita L, Costa I S E A - Estudo comparativo da eficácia do etanol e do ácido L-glutâmico na prevenção da calcificação das cúspides e parede aórtica porcina: estudo experimental em ratos. Rev Bras Cir Cardiovasc 2002; 17(2): 40-51.

rativamente aos obtidos com o glutaraldeído e o etanol a $80 \%$. Do mesmo modo, os estudos histológicos confirmam a superioridade de sua ação ${ }^{(18,42)}$.

Neste estudo, não se pôde comparar os achados quanto à ação do ácido L-glutâmico nas cúspides e parede aórtica porcinas implantadas no subcutâneo de ratos, por não terem sido encontrados estudos semelhantes na literatura.

\section{CONCLUSÕES}

Da análise comparativa de dois métodos de prevenção da calcificação (etanol a $80 \%$ e ácido L-glutâmico a $0,8 \%$ ) em cúspide e parede aórtica porcina em ratos jovens, aos 15 , 30 e 60 dias de implante subcutâneo, concluiu-se que:

O etanol a $\mathbf{8 0} \%$ inibe a calcificação das cúspides nos três períodos analisados, mas não inibe a calcificação da parede aórtica.

0 ácido L-glutâmico a $0,8 \%$ não inibe a calcificação das cúspides nos três períodos analisado, mas minimiza a calcificação na parede da aorta, quando comparado ao grupo controle no intervalo de 60 dias.

RBCCV 44205-585

Soncini da Rosa GR, Costa F D A, Mesquita L, Costa I S E A - Comparative study on the efficacy of ethanol and of I-glutamic acid for preventing calcification of pig cusps and aortic wall: experimental study in rats. Rev Bras Cir Cardiovasc 2002; 17(2): 39-50.

ABSTRACT: Introduction: The glutataldehyde (GDA) treated pigs cusps are one of most employed tissues in bioprosthesis, but is late post-implant calcification is main cause of its failure.

Background: This study aims at comparing and analyzing two methods (ethanol $80 \%$ and Iglutamic acid $0.8 \%$ ) to prevent calcification in pig cusps and aortic wall implanted subcutaneously in rats, the cusps and aortic wall segments of the control were in glutaraldehyde (GDA), during a 15,30 and 60 days period after the implant.

Material and Methods: We used 45 young rats, distributed in 3 groups of 15 rats each, which in turn were subdivided in 3 subgroups of 5 rats each, in which we implanted one cusp and one aortic wall segment in 2 subcutaneous pouches for each rat. We called each group as follows: GDA (control group), E80\% (the group whose structures were previously prepared with ethanol $80 \%$ ) and GA $0.8 \%$ (group previously prepared with L-glutamic acid $0.8 \%$ ); in those groups we measured calcium and performed a microscopic analysis seeking for any calcification, its location and intensity; inflammatory infiltrate, location and type, during a 15, 30, and 60-day period after the implant.

Results: Calcium was found in the aortic cusp in the E80\% group $(1.30 \pm 0.21 \mathrm{mg}$ calcium $/ \mathrm{mg}$ tissue) at day $15,(1.05 \pm 0.22 \mathrm{mg}$ calcium $/ \mathrm{mg}$ tissue) at day 30 , and $(0.53 \pm 0.42 \mathrm{mg}$ calcium $/ \mathrm{mg}$ tissue) at day 60 ; in the GA $0.8 \%$ group $(12.17 \pm 0.66 \mathrm{mg}$ calcium $/ \mathrm{mg}$ tissue) at day $15,(15.31 \pm 2.82$ $\mathrm{mg}$ calcium $/ \mathrm{mg}$ tissue) at day 30 , and $(34.24 \pm 16.28 \mathrm{mg}$ calcium $/ \mathrm{mg}$ tissue) at day 60 ; and in the control group, GDA at day $15(12.44 \pm 2.26 \mathrm{mg}$ calcium $/ \mathrm{mg}$ tissue), at day $30(13.44 \pm 3.34 \mathrm{mg}$ calcium $/ \mathrm{mg}$ tissue), and at day $60(50.85 \pm 8.71 \mu \mathrm{g}$ calcium $/ \mathrm{mg}$ tissue $)$. As for the calcium measured in the aortic wall, in the E80\% group we found $(4.62 \pm 0.68 \mu \mathrm{g}$ calcium $/ \mathrm{mg}$ tissue) at day 15 , $(9.47 \pm 2.59 \mu \mathrm{g}$ calcium $/ \mathrm{mg}$ tissue $)$ at day 30 , and $(23.56 \pm 7.75 \mu \mathrm{g}$ calcium $/ \mathrm{mg}$ tissue) at day 60 ; in the GA $0.8 \%$ group at day $15(4.31 \pm 0.85 \mu \mathrm{g}$ calcium $/ \mathrm{mg}$ tissue $)$, at day $30(7.69 \pm 1.48 \mu \mathrm{g} \mathrm{calcium} /$ $\mathrm{mg}$ tissue), and at day $60(20.50 \pm 1.22 \mu \mathrm{g}$ calcium/mg tissue); and in the control group (GDA) at day $15(7.34 \pm 1.32 \mu \mathrm{g}$ calcium $/ \mathrm{mg}$ tissue), at day $30(9.28 \pm 0.76 \mu \mathrm{g}$ calcium $/ \mathrm{mg}$ tissue), at day 60 $(27.60 \pm 1.08 \mu \mathrm{g}$ calcium $/ \mathrm{mg}$ tissue). Microscopic evaluation of the aortic cusp, showed a progressive calcification in those fixed with GDA. Such process was found partially in the GA $0.8 \%$ group, and totally absent in the E80\% group. As for the assessment of the aortic wall segments, we also observed progressive calcification, which was not inhibited by the treatment with either GA $0.8 \%$ or $\mathrm{E} 80 \%$.

Conclusions: We concluded that a pre-treatment with ethanol at $80 \%$ inhibited calcification in pig aortic cusps, however it was not as effective on the aortic wall. However, L-glutamic acid at $0.8 \%$ did show that it minimizes calcification in the aortic wall. Further studies are required, to evidence if the anti-calcifying action of ethanol $80 \%$ is kept if the pig aortic bioprostheses are implanted in the circulatory system.

DESCRIPTORS: Bioprosthesis, conservation. Ethanol, pharmacology. Glutamic acid, pharmacology. Calcification, physiologic. 
Soncini da Rosa GR, Costa F D A, Mesquita L, Costa I S E A - Estudo comparativo da eficácia do etanol e do ácido L-glutâmico na prevenção da calcificação das cúspides e parede aórtica porcina: estudo experimental em ratos. Rev Bras Cir Cardiovasc 2002; 17(2): 40-51.

\section{REFERÊNCIAS BIBLIOGRÁFICAS}

1. Schoen FJ \& Levy RJ - Current challenges and future research perspectives. Founder's Award, $25^{\text {th }}$ Annual Meeting of the Society for Biomaterials, Providence, RI, April 28-May 2, 1999. Tissue Heart Valves: 1999; 439-65.

2. Cosgrove DM - Valve reconstruction versus valve replacement. In: Crawford FA, ed. Current heart valve prostheses. In: Cardiac Surgery. 1987; 143p.

3. Gott JP, Pan-Chih, Dorsey LM et al. - Calcification of porcine valves: a successful new method of antimineralization. Ann Thorac Surg 1992; 53: 207-16.

4. Ross D - Homograft replacement of the aortic valve. Lancet 1962; 2: 487.

5. Ionescu MI, Wooler GH, Smith DR, Grinshaw V A - Mitral valve replacement with aortic heterografts in humans. Thorax 1967; 22: 305-13.

6. Braile DM et al. - Experiência inicial com emprego das próteses de LILLEHEI-KASTER. Arq Bras Cardiol 1974; 27 (supl. 1): 14.

7. Puig LB \& Verginelli G - Válvulas cardíacas de dura-máter homóloga: nota prévia. $R$ Paul Med 1971; 78: 33-5.

8. Potkin BN, McIntosh CL, Cannon RO ${ }^{\text {rd }}$, Roberts WC - Bioprostheses in tricuspid and mitral valve positions for 100 months with heavier calcific deposits on the left-sided valve followed by new bioprostheses in both positions for 95 months with heavier calcific deposits on the rigth-sided valve. Am J Cardiol 1988; 61: 947-9.

9. Carpentier A, Blondeau P, Laurens P, Mancel P, Laurent D, Dubost C - Remplancement des valvules mitraes et ki cuspides per le'tirogreffes. Ann Clin Thorac Cardiovasc 1968; 7: 33-8.

10. Pelletier LC, Carrier M, Leclerc Y, Lepage G, de Guise P, Dyrda I - Porcine versus pericardial bioprotheses: a comparison of late results in 1,593 patients. Ann Thorac Surg 1989; 47: 352-61.

11. Barratt-Boyes BG - Homograft aortic valve replacement in aortic incompetence and stenosis. Thorax 1964; 19: 131.
12. Carpentier A, Deloche A, Relland J et al. - Sixyear follow-up of glutaraldehyde-preserved heterografts: with particular reference to the treatment of congenital valve malformations. J Thorac Cardiovasc Surg 1974; 68: $771-82$.

13. Carpentier A, Nashef A, Carpentier S, Ahmed A, Goussef N - Techniques for prevention of calcification of valvular bioprostheses. Circulation 1984; 70 (suppl 1): I165-8.

14. Aupart RM et al. - The last generation of pericardial valves in the aortic position. Ann Thorac Surg 1996; 6: 615-20.

15. Jamieson WR et al. - Carpentier-Edwards standard porcine bioprosthesis: clinical performance to seventeen years. Ann Thorac Surg 1995; 60: 999-1007.

16. Scheld HH \& Konertz W - The pathology of bioprosthetic heart valves and allografts. Curr Top Pathol 1994; 86: 87-125.

17. Grunkemeier GL \& Bodnar E - Comparative assessment of bioprosthesis durability in the aortic position. J Heart Valve Dis 1995; 4: 49-55.

18. Vyavahare N, Hirsch D, Lerner E et al.Prevention of bioprosthetic heart valve calcification by ethanol preincubation: efficacy and mechanisms. Circulation 1997; 95: 479-88.

19. Lee $\mathrm{CH}$, Vyavahare $\mathrm{N}$, Zand $\mathrm{R}$ et al. - Inhibition of aortic wall calcification in bioprosthetic heart valves by ethanol pretreatment: biochemical and biophysical mechanisms. J Biomed Mater Res 1998; 42: 30-7.

20.Vyavahare NR, Jones PL, Hirsch D, Schoen FJ, Levy RJ - Prevention of glutaraldehyde - fixed bioprosthetic heart valve calcification by alcohol pretreatment: further mechanistic studies. $J$ Heart Valve Dis 2000; 9: 561-6.

21.Shen M, Kara-Mostefa A, Chen $L$ et al.- Effect of ethanol and ether in the prevention of calcification of bioprostheses. Ann Thorac Surg 2001; 71 (5 Suppl): S413-6.

22. Schoen FJ, Harasaki H, Kim KM, Anderson HC, Levy RJ - Biomaterial-associated calcification: pathology, mechanisms and strategies for prevention. J Biomed Mater Res 1988; 22 (A1 Suppl): 11-36. 
Soncini da Rosa GR, Costa F D A, Mesquita L, Costa I S E A - Estudo comparativo da eficácia do etanol e do ácido L-glutâmico na prevenção da calcificação das cúspides e parede aórtica porcina: estudo experimental em ratos. Rev Bras Cir Cardiovasc 2002; 17(2): 40-51.

23. Golomb G, Schoen FJ, Smith MS, Linden J, Dixon M, Levy RJ - The role of glutaraldehyde - induced cross-links in calcification of bovine pericardium used in cardiac valve bioprotheses. Am J Pathol 1987; 127: $122-30$

24.Grimm M, Eybl E, Grabenwoger M et al. Biocompatibility of aldehyde - fixed bovine pericardium: an in vitro and in vivo approach toward improvement of bioprosthetic heart valves. J Thorac Cardiovasc Surg 1991; 102: 195-201.

25. Grabenwoger M, Grimm M, Eybl E et al. Decreased tissue reaction to bioprosthetic heart valve material after L-glutamic acid treatment: a morphological study. J Biomed Mater Res 1992; 26: 1231-40.

26. Carpentier A, Lemaigre G, Robert L, Carpentier $S$, Dubost C - Biological factors affecting long-term results of valvular hetero-grafts. $J$ Thorac Cardiovasc Surg 1969; 58: 467-83.

27. Grunkemeier GL, Jamieson WR, Miller DC, Starr A - Actuarial versus actual risk of porcine structural valve deterioration. J Thorac Cardiovasc Surg 1994; 108: 70918.

28. Milano A, Guglielmi C, De Carlo M et al. - Valverelated complications in elderly patients with biological and mechanical aortic valves. Ann Thorac Surg 1998; 66: S82-7.

29. Hirsch D, Drader J, Pathak YV, Yee R, Schoen FJ, Levy RJ - Synergistic inhibition of the calcification of glutaraldehyde pretreated bovine pericardium in rat subdermal model by $\mathrm{FeCl}_{3}$ and ethanehydroxydisphosphonate: preincubation and polymeric controlled release studies. Biomaterials 1993; 14: 705-11.

30.Jones M, Eidbo EE, Hilbert SL, Ferrans VJ, Clark RE - The effects of anticalcification treatments on bioprosthetic heart valves implanted in sheep. ASAIO Trans 1988; 34: 1027-30.

31. Chen W, Schoen FJ, Levy RJ - Mechanism of efficacy of 2-amino oleic acid for inhibition of calcification of glutaraldehyde-pretreated porcine bioprosthetic heart valves. Circulation 1994; 90: 323-9.

32. Chen W, Kim JD, Schoen FJ, Levy RJ - Effect of 2-amino oleic acid exposure conditions on the inhibition of calcification of glutaraldehyde cross-linked porcine aortic valves. J Biomed Mater Res 1994; 28: 1485-95.
33. Hirsch D, Drader J, Thomas TJ Schoen FJ, Levy JT, Levy RJ - Inhibition of calcification of glutaraldehyde pretreated porcine aortic valve cusps with sodium dodecyl sulfate: preincubation and controlled release studies. J Biomed Mater Res 1993; 27: 1477-84.

34.Levy RJ, Schoen FJ, Lund SA, Smith MS Prevention of leaflet calcification of bioprosthetic heart valves with diphosphonate injection therapy: experimental studies of optimal dosages and therapeutic durations. J Thorac Cardiovasc Surg 1987; 94: 551-7.

35.Levy RJ, Woffrum J, Schoen FJ, Hawley MA, Lund SA, Langer R - Inhibition of calcification of bioprosthetic heart valves by local controlled-released diphosphonate. Science 1985; 228: 190-2.

36.Vyavahare $\mathrm{N}$ et al. - Synergism of calciumethanehydroxybisphosphonate (CaEHBP) and FeCL3: controlled release polymers for preventing calcification of bioprosthetic aortic. J Control Rel 1995; 34: 34-97.

37.Webb CL, Schoen FJ, Levy RJ - Covalent binding of aminopropanehydroxydisphosphonate to glutaraldehyde residues in pericardial bioprosthetic tissue: stability and calcification inhibition studies. Exp Mol Pathol 1989; 50: 291-302.

38. Jones M, Eidbo EE, Hilbert SL, Ferrans VJ, Clark RE- Anticalcification treatments of bioprosthetic heart valves: in vivo studies in sheep. J Card Surg 1989; 4: 69-73.

39. Golomb G \& Ezra V - Prevention of bioprosthetic heart valve tissue calcification by charge modification: effects of protamine binding by formaldehyde. J Biomed Mater Res 1991; 15: 85-98.

40.Schoen FJ, Levy RJ - Pathophysiology of bioprosthetic heart valve calcification. In: Bodnar E \& Yacoub $\mathrm{MH}$, ed. Biological and bioprosthetic valves. New York: 1986. 418-429p.

41. Schoen FJ, Hirsch D, Bianco RW, Levy RJ Onset and progression of calcification in porcine aortic bioprosthetic valves implanted as orthotopic mitral valve replacements in juvenile sheep. $J$ Thorac Cardiovasc Surg 1994; 108: 880-7.

42.Weissenstein C, Human P, Bezuidenhout D, Zilla $P$ - Glutaraldehyde detoxification in addition to enhanced amine cross-linking dramatically reduces bioprosthetic tissue calcification in the rat model. $J$ Heart Valve Dis 2000; 9: 230-40. 